\title{
In Situ TDLAS Measurement of Absolute Acetylene Concentration Profiles in a Non-Premixed Laminar Counter Flow Flame
}

\author{
S. Wagner ${ }^{1,2}$, M. Klein ${ }^{1}$, T. Kathrotia ${ }^{3}$, U. Riedel ${ }^{3}$, T. Kissel ${ }^{1}$, A. Dreizler ${ }^{1}$, V. Ebert ${ }^{* 1,2}$ \\ ${ }^{1}$ Fachgebiet Reaktive Strömungen und Messtechnik, Center of Smart Interfaces, Technische \\ Universität Darmstadt, Petersenstr. 32, 64287 Darmstadt, Germany \\ ${ }^{2}$ Physikalisch-Technische Bundesanstalt, Bundesallee 100, 38116 Braunschweig, Germany \\ ${ }^{3}$ Universität Stuttgart and Institute of Combustion Technology, German Aerospace Center, \\ Pfaffenwaldring 38-40, 70569 Stuttgart, Germany
}

Appl Phys B (2012), Volume 107, page 585-589

The original publication is available at www.springerlink.com

http://dx.doi.org/10.1007/s00340-012-4953-5 


\title{
In Situ TDLAS Measurement of Absolute Acetylene Concentration Profiles in a Non-Premixed Laminar Counter Flow Flame
}

\author{
S. Wagner ${ }^{1,2}$, M. Klein ${ }^{1}$, T. Kathrotia ${ }^{3}$, U. Riedel ${ }^{3}$, T. Kissel $^{1}$, A. Dreizler $^{1}$, V. Ebert $^{* 1,2}$
}

1 Fachgebiet Reaktive Strömungen und Messtechnik, Center of Smart Interfaces, Technische Universität Darmstadt, Petersenstr. 32, 64287 Darmstadt, Germany

2 Physikalisch-Technische Bundesanstalt, Bundesallee 100, 38116 Braunschweig, Germany

3 Universität Stuttgart and Institute of Combustion Technology, German Aerospace Center, Pfaffenwaldring 38-40, 70569 Stuttgart, Germany

$\begin{array}{ll}\text { Corresponding author: Volker Ebert } & \\ \text { Phone: } & +49(0) 5315923200 \\ \text { Fax: } & +49(0) 5315923209 \\ \text { Email: } & \quad \text { volker.ebert@ptb.de }\end{array}$




\section{Abstract}

Acetylene $\left(\mathrm{C}_{2} \mathrm{H}_{2}\right)$ as an important precursor for chemiluminescence species, is a key to understand, simulate and model the chemiluminescence and the related reaction paths. Hence we developed a high resolution spectrometer based on direct Tunable Diode Laser Absorption Spectroscopy (TDLAS) allowing the first quantitative, calibration-free and spatially resolved in situ $\mathrm{C}_{2} \mathrm{H}_{2}$ measurement in an atmospheric non-premixed counter-flow flame supported on a Tsuji burner. A fiber-coupled distributed feedback diode laser near $1535 \mathrm{~nm}$ was used to measure several absolute $\mathrm{C}_{2} \mathrm{H}_{2}$ concentration profiles (peak concentrations up to $9700 \mathrm{ppm}$ ) in a laminar non-premixed $\mathrm{CH}_{4} /$ air flame ( $T$ up to $1950 \mathrm{~K}$ ) supported on a modified Tsuji counter flow burner with $\mathrm{N}_{2}$ purge slots to minimize end flames. We achieve a fractional optical resolution of up to $5 \times 10^{-5}$ OD $(1 \sigma)$ in the flame, resulting in temperature dependent acetylene detection limits for the P17e line at $6513 \mathrm{~cm}^{-1}$ of up to $2.1 \mathrm{ppm} \cdot \mathrm{m}$. Absolute $\mathrm{C}_{2} \mathrm{H}_{2}$ concentration profiles were obtained by translating the burner through the laser beam using a DC motor with $100 \mu \mathrm{m}$ step widths. Intercomparisons of the experimental $\mathrm{C}_{2} \mathrm{H}_{2}$ profiles with simulations using our new hydrocarbon oxidation mechanisms show excellent agreement in position, shape and in the absolute $\mathrm{C}_{2} \mathrm{H}_{2}$ values.

\section{Introduction}

In order to increase the efficiency and avoid the production of unwanted pollutants the operating conditions of modern combustion processes are more and more shifted towards "instable" modes of operation. Thus, optimized active combustion control is required to achieve further improvements preferably using passive, optimized combustion sensors. Flame chemiluminescence $(\mathrm{CL})$ shows an interesting potential for a completely passive and inexpensive combustion control sensor. Therefore the development of innovative strategies of chemiluminescence detection and analysis based on sophisticated $\mathrm{C}_{1}-\mathrm{C}_{4}$ hydrocarbon oxidation mechanism and chemiluminescence model extensions is necessary. The important chemiluminescent radicals $\mathrm{C}_{2}{ }^{*}$ and $\mathrm{CH}^{*}$ are formed via their direct intermediate precursor species $\mathrm{C}_{2} \mathrm{H}$ and ${ }^{3} \mathrm{CH}_{2}$, who on the other hand are direct products of the acetylene $\left(\mathrm{C}_{2} \mathrm{H}_{2}, \mathrm{H}-\mathrm{C} \equiv \mathrm{C}-\mathrm{H}\right)$ removal in the flame. $[1,20,32]$. Hence, the absolute concentration and 
spatial distribution of the $\mathrm{C}_{2} \mathrm{H}_{2}$ produced during hydrocarbon combustion is a key parameter to understand and model the reaction paths towards formation of chemiluminescent species, the better understanding of the spatial distribution of the chemiluminecence and finally the use of chemiluminecence signals for combustion control purposes e.g. as a passive indicators for local heat release. $\mathrm{C}_{2} \mathrm{H}_{2}$ also plays an important role in soot formation [2,3], the formation of polycyclic aromatic hydrocarbons [4], or nano particles [5] as well as chemical vapor deposition processes [6].

Under combustion conditions Acetylene has been a rather difficult target species even tough techniques like Diode Laser Wavelength Modulation Spectroscopy (DL-WMS) [7], Infrared Polarization Spectroscopy (IRPS) [8,9], Gas Chromatography (GC) [10,11], GC coupled Mass Spectroscopy (GC/MS) [12,13], Coherent Anti-Stokes Raman Spectroscopy (CARS) [14], Raman [15,16], Laser Induced Fluorescence (LIF) [17] or extractive Tunable Diode Laser Absorptions Spectroscopy (TDLAS) [18] were applied for $\mathrm{C}_{2} \mathrm{H}_{2}$ detection in flames over the last years. Common drawbacks of these approaches are the need for sensor calibration or limitations regarding sensitivity, spatial or temporal resolution.

For an improved understanding of flame $\mathrm{CL}$, or the validation of modern flame models, detailed experimental in situ species data are necessary like the spatial $\mathrm{C}_{2} \mathrm{H}_{2}$ distribution in simple testing systems like laminar diffusion flames.

For this purpose we further developed direct absorption spectroscopy as a powerful tool to provide robust, absolute and calibration-free $\mathrm{C}_{2} \mathrm{H}_{2}$ concentration measurements.

Here we present a new TDLAS in situ spectrometer for $\mathrm{C}_{2} \mathrm{H}_{2}$ detection, its application to spatially resolved $\mathrm{C}_{2} \mathrm{H}_{2}$ concentration profile measurements inside a laminar diffusion flame, and the validation of the results via the intercomparison with flame simulations.

\section{Burner Setup and Flame Structure}

The $\mathrm{C}_{2} \mathrm{H}_{2}$ in-flame measurements were realized in a modified $\mathrm{CH}_{4}$ /air Tsuji burner (Type IV) $[10,19,20]$ with a stabilized counter-flow flame. Here a U-shaped flame is formed by ejecting 
methane with a velocity $\left(v_{\text {air }}\right)$ of $0.18 \mathrm{~m} / \mathrm{s}$ from the top trough a cylindrical sintered matrix with a radius $r_{\text {burner }}=20 \mathrm{~mm}$ into a laminar upward air-stream (see Fig.1). Along a vertical line through the flow stagnation point, this configuration can be treated as a one dimensional problem which significantly simplifies the simulation of the flame and its combustion chemistry. This flame is particularly important as it allows a controlled variation of the flame stretch, i.e. the so called strain rate

$a=2 \cdot v_{\text {air }} / r_{\text {burner }}$.

which is an important turbulent flame parameter.

Tsuji flames are well suited for absorption measurements. Nevertheless significant errors are caused by the slight flame front curvature in the so called end flames [21]. To minimize this effect, ensure a uniform, flat flame front with defined flame ends and thus improve the accuracy of Tsuji absorption measurements, we modified Tsuji's burner design by adding $\mathrm{N}_{2}$ co-flow nozzles to suppress the both end flames. This results in a very homogeneous absorption path of $60 \mathrm{~mm}$.

Spatially resolved species profiles were measured by shifting the burner vertically within the air duct in $100 \mu \mathrm{m}$ steps via a software controlled DC motor connected to a high resolution translation stage. The resolution of the translation stage i.e. the smallest step of the motor was $0.5 \mu \mathrm{m}$.

\section{Direct Absorption Spectroscopy}

For the in situ $\mathrm{C}_{2} \mathrm{H}_{2}$ detection we used our variant of direct absorptions spectroscopy [22-24] which permits calibration-free measurements of absolute species concentrations, gas temperatures or gas residence time distributions [22-27]. In harsh environments where calibration is extremely difficult or even impossible one can strongly benefit from this approach. In contrast to Wavelength Modulation Spectroscopy (WMS), Frequency Modulation Spectroscopy (FMS) or dual beam techniques the dccoupled detector signal, including all offsets and disturbances is directly digitized and used in the data evaluation. To recover the complete absorption line shape only wavelength scanning with linear ramp-like current scanning is needed. The diode laser beam was directed through the detection 
volume and the resulting signal detected by a photo diode. Assuming a homogeneously absorbing medium we use the extended Lambert-Beer-law

$I(\lambda)=E(t)+I_{0}(\lambda) \cdot \operatorname{Tr}(t) \cdot \exp \left[-S(T) \cdot g\left(\lambda-\lambda_{0}\right) \cdot N \cdot L\right]$

Therein $I_{0}(\lambda)$ describes the initial and $I(\lambda)$ the transmitted laser intensity. The absorption signal is described by the temperature-dependent line strength $S(T)$, the absorber number density $N$, the absorption path length $L$, and the normalized line shape function $g\left(\lambda-\lambda_{0}\right)$, which is centered at wavelength $\lambda_{0} . \operatorname{Tr}(t)$ describes fluctuations of the broadband overall transmission that may be present and which can be caused by broadband absorption, light scattering by particles or beam steering. $E(t)$ usually describes background radiation, which would increase the detected signal and thus must be subtracted from the transmitted laser light. Combining the ideal gas law and the Lambert-Beer-law allows extraction of the absolute species concentration from the integrated absorption line area.

\section{In-flame TDLAS spectrometer setup}

A single mode, fiber-coupled, continuously tunable, near infrared distributed feedback diode laser (DFB), with an emission wavelength near $1.53 \mu \mathrm{m}$ was used as light source for the absorption spectrometer. This laser shows an excellent laser linewidth of low single digit $\mathrm{MHz}$, a high spectral stability and due to the single mode fiber coupling a well-defined, Gaussian beam shape. The laser was precisely characterized regarding spectral purity, stability and static as well as dynamic wavelength tuning characteristics [28][Fig.2].

Due to the high flame temperatures the $\mathrm{C}_{2} \mathrm{H}_{2}$ spectrum suffers from severe interference by the dense water vapor spectrum. In a previous study on $\mathrm{C}_{2} \mathrm{H}_{2}$-TDLAS line selection [22] we showed that the P17e line in the $v_{1}+v_{3}$ combination band at $6512.99 \mathrm{~cm}^{-1}$ is best suited for in situ $\mathrm{C}_{2} \mathrm{H}_{2}$ TDLAS measurements in flame environments.

In the present study the laser wavelength is scanned over a $1.46 \mathrm{~cm}^{-1}$ spectral interval with a repetition frequency of $140 \mathrm{~Hz}$, using a triangular laser current modulation. The laser light emitted 
from the FC/APC (Fiber Connector/Angled Physical Contact) terminated single mode fiber (fiber-NA $0.15)$ is collimated by an aspheric lens $\left(\mathrm{d}_{\text {Beam }}=1 \mathrm{~mm}\right)$. Gold coated bending mirrors direct the collimated beam through two $0.5 \mathrm{~mm}$ pin holes (separated by $100 \mathrm{~mm}$ ) placed adjacent to the flame and define therefore the spatial resolution in the vertical direction. A $90^{\circ}$ off-axis parabolic mirror collects the laser light and focuses it onto a standard $1 \mathrm{~mm}^{2} \mathrm{InGaAs}$ detector. The resulting photo current is amplified with a low noise transimpedance amplifier ( $500 \mathrm{kHz}$ bandwidth) and then digitized with an 18-bit ADC at 140 kSamples/sec. After correction for transmission and emission errors the individual absorption line area is determined using an in house, Labview-based, recursive Levenberg-Marquardt algorithm. As fitting model we use a background polynomial of up to $4^{\text {rd }}$ order and an array of multiple Voigt line shapes.

The fitting process was stabilized and optimized by calculating preset values for Doppler as well as collisional broadening, using measured values of the total pressure, the gas temperature and the foreign broadening coefficients (publication in preparation) of the $\mathrm{C}_{2} \mathrm{H}_{2}$ lines. Further, the multiVoigt-line fit makes use of spectral data from HITRAN2008 [29] as well as HITEMP2010 [30] and includes the precisely measured dynamic tuning behavior of the laser.

Spatially resolved, highly accurate and absolute in flame temperature profiles were determined with a vertical spatial resolution of $65 \mu \mathrm{m}$ along the stagnation line via $\mathrm{N}_{2}$ ro vibrational CARS [31].

The measured $\mathrm{C}_{2} \mathrm{H}_{2}$ spatial profiles were compared to our own flame simulation results [32]. Our simulations of the non-premixed flame in one-dimensional Tsuji counter flow geometry was performed with the flame code INSFLA [33,34].

\section{Results and discussion}

Fig.3 shows a typical example of a transmission corrected in situ absorption signal of the $\mathrm{P} 17 \mathrm{e} \mathrm{C}_{2} \mathrm{H}_{2}$ line (pattern) and the surrounding, disturbing $\mathrm{H}_{2} \mathrm{O}$ absorption lines.

Our combination of a multiple Voigt line fitting and optical disturbance correction algorithms results in highly resolved absorption line profiles in the Tsuji burner flame. By averaging over 500 scans 
corresponding to 7.5 seconds temporal resolution, we achieved an excellent fractional optical resolution of $5.1 \times 10^{-5}$. This resolution is derived from the $1 \sigma$ average of the total residual as shown in Fig.3. From the peak absorbance of $6.8 \times 10^{-4}$ and the average residual we derive a signal to noise ratio of more than 13. At $\mathrm{T}=1500 \mathrm{~K}$, i.e. $2.2 \mathrm{~mm}$ above the burner surface we find a $\mathrm{C}_{2} \mathrm{H}_{2}$ mixing ratio of $5218 \mathrm{ppm}$. From the residual we derive a $1 \sigma$ detection limit of $391 \mathrm{ppm}$, corresponding to a normalized detection limit of $23.5 \mathrm{ppm} \cdot \mathrm{m}\left(64.4 \mathrm{ppm} \cdot \mathrm{m} \cdot \mathrm{Hz}^{-0.5}\right)$.

The vertical translation of the burner head relative to the laser beam yields absolute, in flame $\mathrm{C}_{2} \mathrm{H}_{2}$ concentration profiles. Fig. 4 depicts the first spatial $\mathrm{C}_{2} \mathrm{H}_{2}$ concentration profile for strain rates from $100 s^{-1}$ to $200 s^{-1}$.

The bold error bars in Fig. 4 left are derived from the uncertainties in the absorption path length, the line strength at $296 \mathrm{~K}$ (HITRAN) and the optical resolution (see Fig.3). The thin error bars stem solely from the temperature uncertainties of the CARS measurements. These comprise the CARS uncertainties of up to $\pm 48 \mathrm{~K}$ and its influence on the calculation of the temperature dependent $\mathrm{C}_{2} \mathrm{H}_{2}$ line strength.

The excellent fractional optical resolution of the inflame $\mathrm{C}_{2} \mathrm{H}_{2}$ profiles leads with peak concentrations up to $9700 \mathrm{ppm}$ to temperature dependent acetylene detection limits of 2.1 to $59.4 \mathrm{ppm} \cdot \mathrm{m}$.

In comparison to the model data we achieve excellent agreement in the peak position, the profile shape and the absolute $\mathrm{C}_{2} \mathrm{H}_{2}$ values. Minor differences in the peak position can be attributed to measurement errors of the fuel ejection rate and the air velocity. Overall we achieved an excellent agreement between model based data and experiment.

\section{Conclusion}

We present the first, absolute and calibration free in situ TDLAS measurements of $\mathrm{C}_{2} \mathrm{H}_{2}$ in a laminar, non-premixed diffusion flame of the Tsuji type burner. We achieved optical resolution of up to $5 \mathrm{x}$ $10^{-5} \mathrm{OD}(1 \sigma)$ and acetylene detection limits of up to $2.1 \mathrm{ppm} \cdot \mathrm{m}\left(5.8 \mathrm{ppm} \cdot \mathrm{m} \cdot \mathrm{Hz}{ }^{-0.5}\right)$. Furthermore we successfully investigate the dependence of the $\mathrm{C}_{2} \mathrm{H}_{2}$ concentration profiles on three different strain 
rates. We also show the first comparison of the measured in situ $\mathrm{C}_{2} \mathrm{H}_{2}$ TDLAS data with improved flame simulations using a new hydrocarbon mechanism and achieve excellent agreement between simulated and measured $\mathrm{C}_{2} \mathrm{H}_{2}$ concentration profiles, which is also remarkable since the in situ TDLAS data are determined without the use of any spectrometer calibration step and without any gas extraction or sample modification.

\section{Outlook}

The Tsuji flame data will be improved further by investigating the dependence of the $\mathrm{C}_{2} \mathrm{H}_{2}$ profile on strain rate, on fuel composition and on flame type (premixed flames) as well as the measurement of other species like $\mathrm{CH}_{4}, \mathrm{H}_{2} \mathrm{O}, \mathrm{OH}$ or $\mathrm{CO}$ in the Tsuji flames using the TDLAS method.

\section{Acknowledgment}

We gratefully acknowledge the financial support of the DFG (Deutsche Forschungsgemeinschaft) project number DFG EB 235/2-1, DFG EB 235/2-2, DFG RI 839/4-2 and EXC 259 (Center of Smart Interfaces).

\section{References}

[1] H.N. Najm, P.H. Paul, C.J. Mueller, P.S. Wyckoff, Combustion and Flame 113 (1998) 312-332.

[2] I. Glassman, Proc. Combust. Inst. 22 (1989) 295- 311.

[3] P. Lindstedt, Proc. Combust. Inst. 27 (1998) 269-285.

[4] H. Richter, J. Howard, Progress in Energy and Combustion Science 26 (2000) 565-608.

[5] J.-M. Bonard, M. Croci, C. Klinke, F. Conus, I. Arfaoui, T. Stöckli, A. Chatelain, Physical Review B 67 (2003) 085412.

[6] A. Dollet, Surface and Coatings Technology 177-178 (2004) 245-251.

[7] Z.R.Z.R. Quine, K.L.K.L. McNesby, Applied Optics 48 (2009) 3075-83. 
[8] Z.S. Li, M. Linvin, J. Zetterberg, J. Kiefer, M. Aldén, Proc. Combust. Inst. 31 (2007) 817-824.

[9] Z.W. Sun, Z.S. Li, B. Li, Z.T. Alwahabi, M. Aldén, Applied Physics B 101 (2010) 423-432.

[10] H. Tsuji, I. Yamaoka, Proc. Combust. Inst. 13 (1971) 723-731.

[11] F. Xu, Combustion and Flame 71 (2000) 593-650.

[12] M.J. Castaldi, A.M. Vincitore, S.M. Senkan, Combustion Science and Technology 107 (1995) $1-19$.

[13] T. Melton, Proc. Combust. Inst. 27 (1998) 1631-1637.

[14] N. Chai, S.V. Naik, W.D. Kulatilaka, N.M. Laurendeau, R.P. Lucht, S. Roy, J.R. Gord, Applied Physics B 87 (2007) 731-737.

[15] A.V. Mokhov, B.A.V. Bennett, H.B. Levinsky, M.D. Smooke, Proc. Combust. Inst. 31 (2007) 997-1004.

[16] A. Mokhov, S. Gersen, H. Levinsky, Chemical Physics Letters 403 (2005) 233-237.

[17] B.A. Williams, J.W. Fleming, Applied Physics B: Lasers and Optics 75 (2002) 883-890.

[18] S. Gersen, A.V. Mokhov, H.B. Levinsky, Combustion and Flame 143 (2005) 333-336.

[19] I. Yamaoka, H. Tsuji, in:, Proc. Combust. Inst., Elsevier, 1977, pp. 1145-1154.

[20] B. Prabasena, M. Röder, C. Hecht, T. Kathrotia, U. Riedel, T. Dreier, C. Schulz, "Strain rate and fuel composition dependence of chemiluminescent species profiles in counterflow diffusion flames: comparison with model results", Appl. Phys. B in press (2012).

[21] S. Wagner, B.T. Fisher, J. Fleming, V. Ebert, Proc. Combust. Inst. 32 (2009) 839-846.

[22] H. Teichert, T. Fernholz, V. Ebert, Applied Optics 42 (2003) 2043-51. 
[23] H.E. Schlosser, J. Wolfrum, V. Ebert, B.A Williams, R.S. Sheinson, J.W. Fleming, Proc. Combust. Inst. 29 (2002) 353-360.

[24] C. Schulz, A. Dreizler, V. Ebert, J. Wolfrum, in:, C. Tropea, A. Yarin, J. Foss (Eds.), Handbook of Experimental Fluid Mechanics, Springer Berlin Heidelberg, Heidelberg, 2007, pp. 1241-1316.

[25] V. Ebert, H. Teichert, P. Strauch, T. Kolb, H. Seifert, J. Wolfrum, Proc. Combust. Inst. 30 (2005) 1611-1618.

[26] A.R. Awtry, J.W. Fleming, V. Ebert, Optics Letters 31 (2006) 900-902.

[27] A.R. Awtry, B.T. Fisher, R.A. Moffatt, V. Ebert, J.W. Fleming, Proc. Combust. Inst. 31 (2007) 799-806.

[28] H. Teichert, T. Fernholz, V. Ebert, Applied Optics 42 (2003) 2043-51.

[29] L.S. Rothman, I.E. Gordon, A. Barbe, D.C. Benner, P.F. Bernath, M. Birk, V. Boudon, L.R. Brown, A. Campargue, J.-P. Champion, Journal of Quantitative Spectroscopy and Radiative Transfer 110 (2009) 533-572.

[30] L.S. Rothman, I.E. Gordon, R.J. Barber, H. Dothe, R.R. Gamache, A. Goldman, V.I. Perevalov, S.A. Tashkun, J. Tennyson, Journal of Quantitative Spectroscopy and Radiative Transfer 111 (2010) 2139-2150.

[31] A.C. Eckbreth, Laser Diagnostics for Combustion Temperature and Species, Taylor \& Francis, 1996.

[32] T. Kathrotia, U. Riedel, A. Seipel, K. Moshammer, A. Brockhinke, “Experimental and numerical study of chemiluminescent species in low-pressure flames", Appl. Phys. B in press (2012).

[33] U. Maas, Applications of Mathematics 3 (1995) 249-266.

[34] U. Maas, J. Warnatz, Combustion and Flame 74 (1988) 53-69. 



\section{Figure Captions}

Figure 1 Schematic of a Tsuji-type burner head. The fuel is ejected through the sintered brass material and forms in the counter propagating air flow a cylindrical flame front coaxially located around the brass cylinder.

Figure 2 Wavelength tuning characteristics of the $1.53 \mu \mathrm{m}$ DFB diode laser. The temperature tuning range is shown in comparison with a HITRAN simulated spectrum [29]. The spectral area around the $\mathrm{C}_{2} \mathrm{H}_{2}-\mathrm{P} 17$ line is populated with a high number of $\mathrm{H}_{2} \mathrm{O}$ absorption lines.

Figure 3 Experimental, emission and transmission corrected TDLAS line profiles and model fit data of the P17e $\mathrm{C}_{2} \mathrm{H}_{2}$ absorption line as well as the interfering $\mathrm{H}_{2} \mathrm{O}$ spectrum, combining $228 \mathrm{H}_{2} \mathrm{O}$ lines.

Figure 4 Experimental in situ TDLAS $\mathrm{C}_{2} \mathrm{H}_{2}$ profiles (points) for strain rates of a=100, 150, $200 \mathrm{~s}^{-1}$ in comparison with simulated flame data (line) using an improved hydrocarbon mechanism. Even the TDLAS signal was not calibrated we achieve excellent agreement in peak position, peak shape and $\mathrm{C}_{2} \mathrm{H}_{2}$ magnitude. 


\section{Figures}
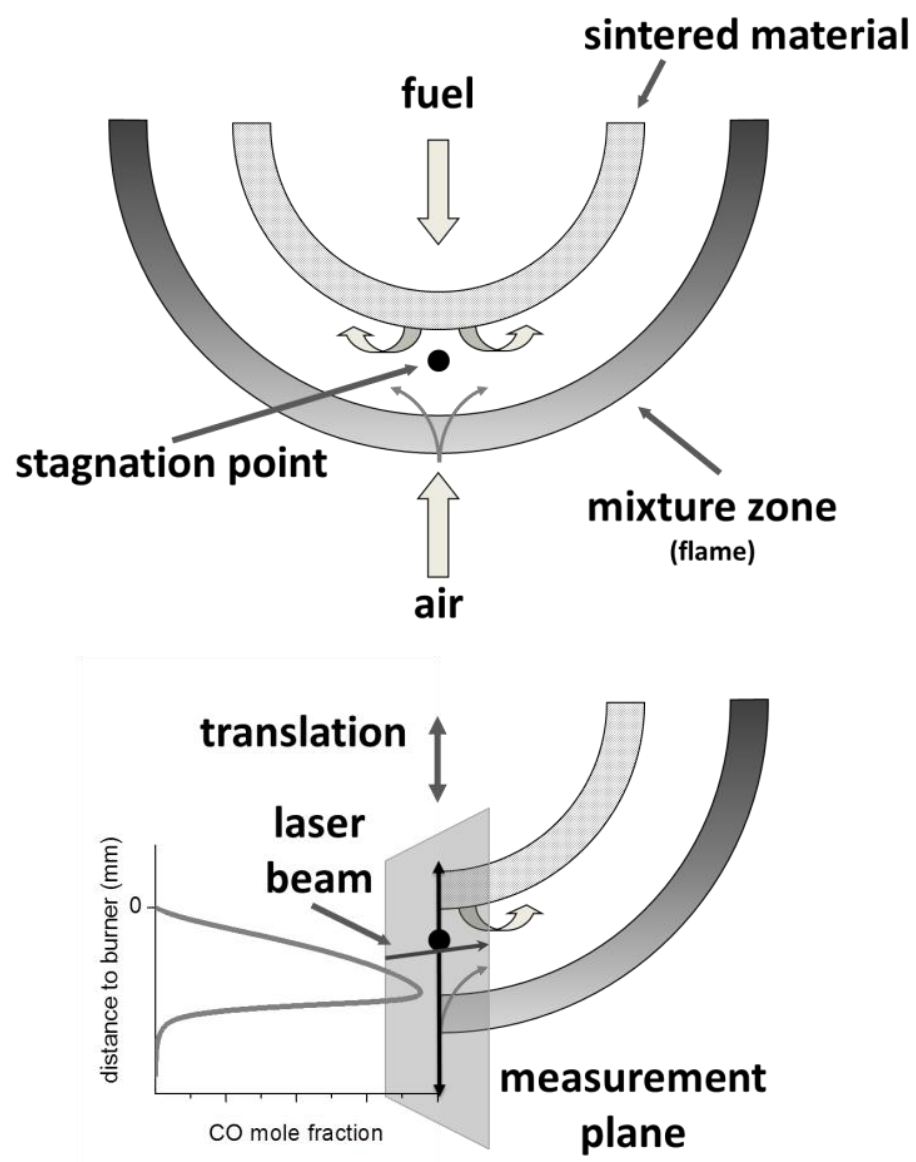

Figure 1 Schematic of a Tsuji-type burner head. The fuel is ejected through the sintered brass material and forms in the counter propagating air flow a cylindrical flame front coaxially located around the brass cylinder. 


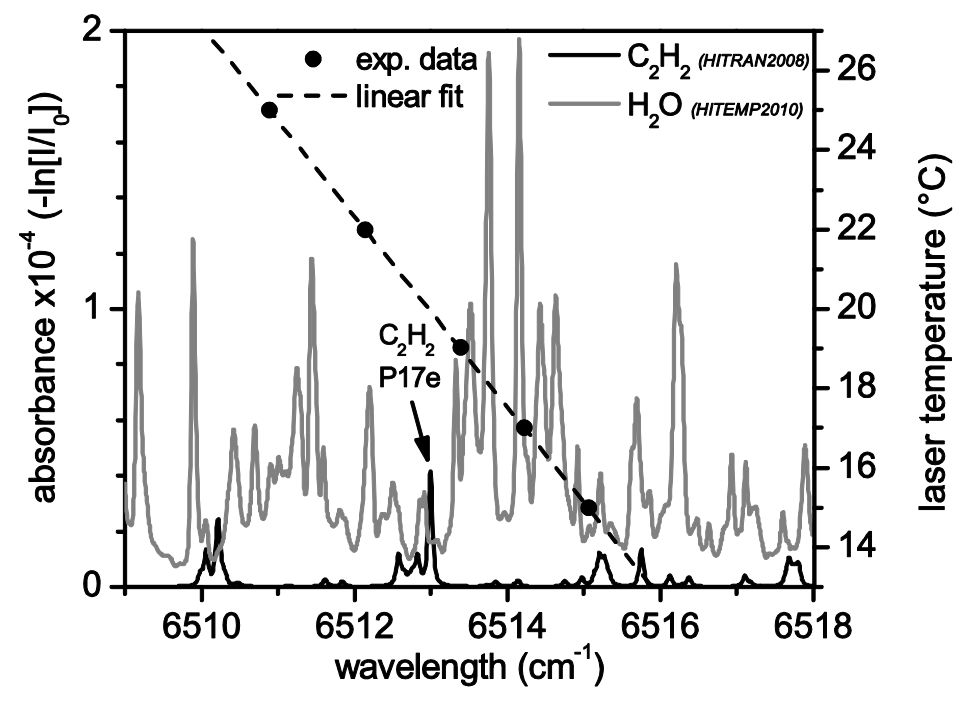

Figure 2 Wavelength tuning characteristics of the $1.53 \mu \mathrm{m}$ DFB diode laser. The temperature tuning range is shown in comparison with a HITRAN simulated spectrum [29]. The spectral area around the $\mathrm{C}_{2} \mathrm{H}_{2}-\mathrm{P} 17$ line is populated with a high number of $\mathrm{H}_{2} \mathrm{O}$ absorption lines. 


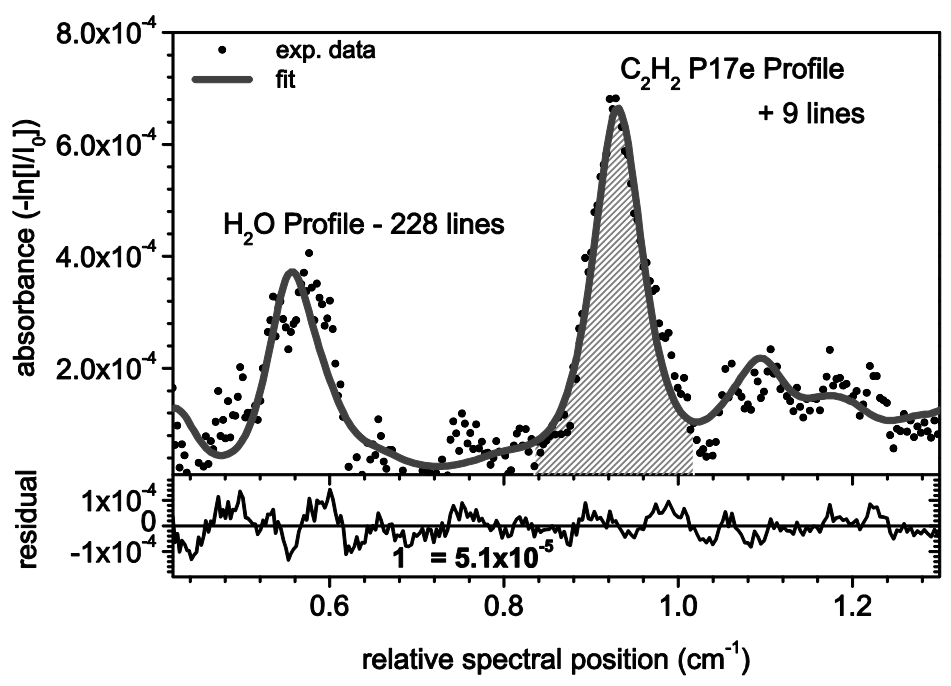

Figure 3 Experimental, emission and transmission corrected TDLAS line profiles and model fit data of the $\mathrm{P} 17$ e $\mathrm{C}_{2} \mathrm{H}_{2}$ absorption line as well as the interfering $\mathrm{H}_{2} \mathrm{O}$ spectrum, combining $228 \mathrm{H}_{2} \mathrm{O}$ lines. 


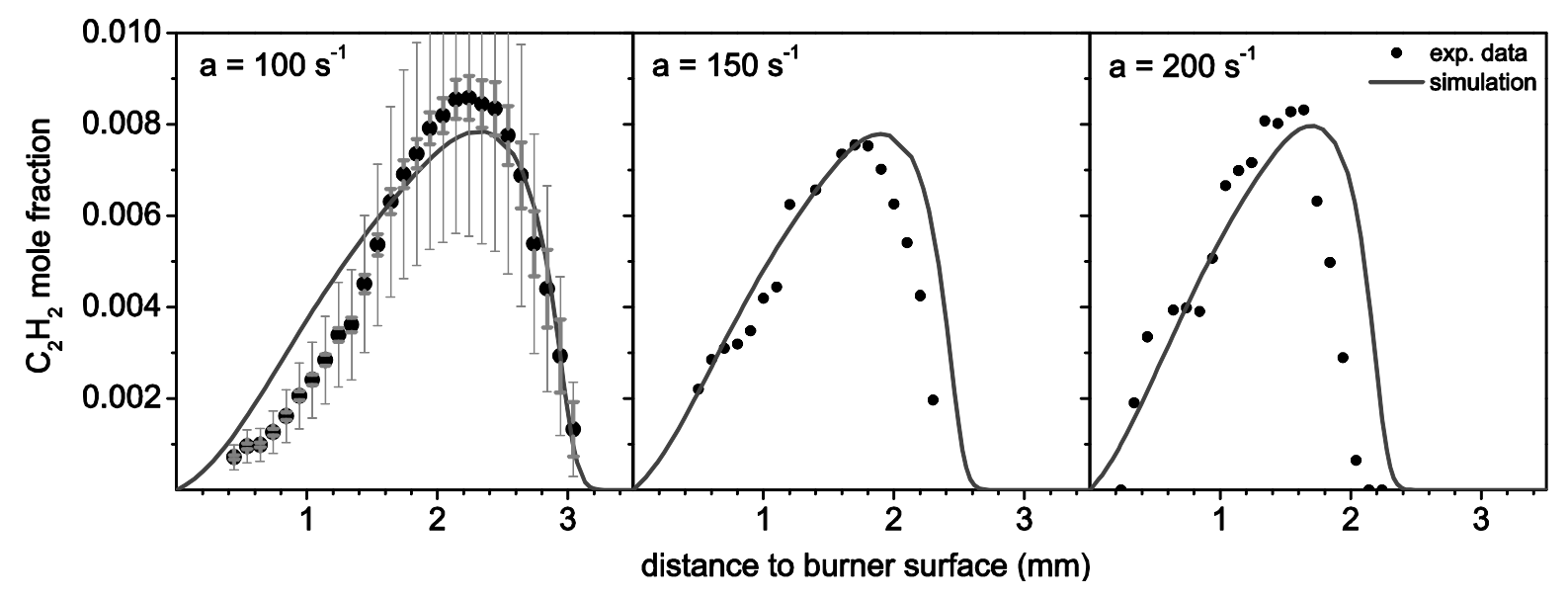

Figure 4 Experimental in situ TDLAS $\mathrm{C}_{2} \mathrm{H}_{2}$ profiles (points) for strain rates of a=100, 150, $200 \mathrm{~s}^{-1}$ in comparison with simulated flame data (line) using an improved hydrocarbon mechanism. Even the TDLAS signal was not calibrated we achieve excellent agreement in peak position, peak shape and $\mathrm{C}_{2} \mathrm{H}_{2}$ magnitude. 